\title{
Commentary: Contextualizing Neuroticism in the Hierarchical Taxonomy of Psychopathology
}

\author{
Bertus F. Jeronimus ${ }^{1,2 *}$ \\ ${ }^{1}$ Department of Developmental Psychology, Faculty of Social and Behavioural Sciences, University of Groningen, Groningen, \\ Netherlands, ${ }^{2}$ Interdisciplinary Center Psychopathology and Emotion Regulation, Department of Psychiatry, University \\ Medical Center Groningen, University of Groningen, Groningen, Netherlands
}

Keywords: personality, emotional stability, developmental perspective, longitudinal, happiness, frustration

\section{A Commentary on}

Contextualizing Neuroticism in the Hierarchical Taxonomy of Psychopathology

by Brandes, C. M., and Tackett, J. L. (2019). J. Res. Pers. 81, 238-245. doi: 10.1016/j.jrp.2019.06.007

Although I agree with most of the great review by Brandes and Tackett (1) about the connection between neuroticism and psychopathology as conceptualized in the Hierarchical Taxonomy of Psychopathology (HiTOP), there are several limitations and future research directions on which I wish to elaborate. First, and most fundamental, I welcome the aims of the HiTOP model to overcome some limitations of categorical diagnostic systems (2). However, the HiTOP frequency-approach remains largely similar to the Diagnostic and Statistical Manual of Mental Disorders [DSM-5, (3)] insofar that it negates the time dimension and most intra-individual dynamics and developmental interconnections between the various system levels [e.g., Fisher et al. (4), Jeronimus (5), and Molenaar (6)], from emotions [over hours, e.g., Kuppens et al. (7)] to mood problems [over weeks, e.g., Wichers (8)] and interpersonal and personality processes [over months and years, e.g., Hopwood (9) and Mobbs (10)], their co-development [e.g., Durbin and Hicks (11) and Ormel et al. (12)], underlying processes [e.g., Kunnen et al. (13)] and origins [e.g., Kendler et al. (14); or Nickels et al. (15) for some problems with the HiTOP], among others. For example, in line with the HiTOP model, Brandes and Tackett cover the time dimension only in Table 1 and on page 242. Neuroticism may be linked to the emergence of symptoms and psychopathology [(1), p. 243] but proof requires studies and manipulations that cover intra-individual changes across various time scales [e.g., Jeronimus (5) and Hamaker and Wichers (16)]. Hence, the inclusion of developmental and dynamic process-perspectives and methodology would make the HiTOP approach even more relevant and exciting. For example, the $25 \%$ of the Dutch population with the highest neuroticism scores seem to generate over $80 \%$ of all mental health costs (17), but a strictly dimensional or spectrum perspective cannot explain why many people with high neuroticism scores do not develop disorders and are healthy and happy (as illustrated in Figure $\mathbf{1}$ below) ${ }^{1}$. Health is a multidimensional state and in certain circumstances high levels of neuroticism can benefit health (20), such as when combined high conscientiousness [e.g., healthy neurotic; Turiano et al. (21) and Weston and Jackson (22)] or in interaction with various other personal strengths [e.g., Bos et al. (23) and Tamir et al. (24)]. Furthermore, high scores on the neuroticism facets worry and vulnerability predict longer lives (25). Future work shall show us in more detail what we can learn from healthy and happy neurotics.

Another limitation is the stipulation that neuroticism is the most difficult personality dimension to measure in infants, toddlers, and children [(1), p. 239]. Others have reported that the neuroticism items in self-reported Big Five personality

\footnotetext{
${ }^{1}$ Which also requires an explanation if neuroticism is equated to the general factor $P$ [see Brandes and Tackett (1), p. 241].
} 


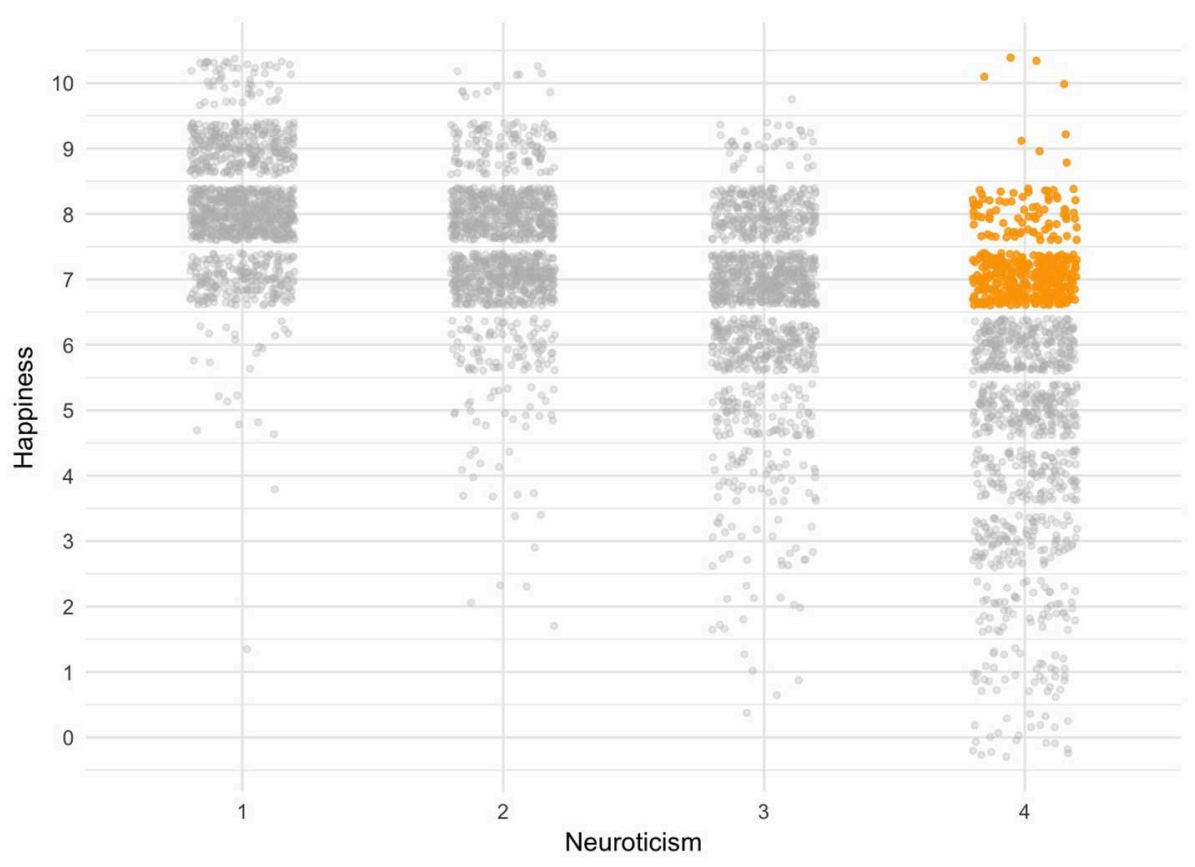

FIGURE 1 | Happy neurotics are depicted in gold. This figure shows 5,000 participants of the HowNutsAreTheDutch study [age range 18-87, mean is 46 (SD = 15), $69 \%$ women, see van der Krieke et al. (18) for details] who completed the neuroticism scale of the NEO-PI-3 (48 items with Likert scale 1-5). Horizontally you see the neuroticism scale subdivided over four quartiles. The golden section indicates the 10\% of the people with the highest neuroticism scores (top 25\% or Q4) who report to be happy, which I defined as the top $25 \%$ (Q4) of happiness scores [scale 0-10, which ranges from the lowest (=0) to highest (=10) wellbeing one can imagine, see Abdel-Khalek (19)].

questionnaires may reflect the personality dimension that was most easy to comprehend by children [e.g., Soto et al. (26)]. Moreover, individual differences in negative affect and patterns of emotion dynamics can be reliably observed in fetuses (27) and infants (28) and remains the backbone of personality differences along the lifespan [e.g., Houben et al. (29), Jeronimus (30), and Reitsema et al. (31)]. Although we agree that anxiety, sadness, and worry are subjective and potentially hidden within the mind, our avoidance behaviors and inhibitory control, irritability/anger and frustration tolerance surface easily and can be reliably measured [e.g., Caspi et al. (32) and Jeronimus et al. (33)], especially in trait relevant situations [e.g., Hirschmüller et al. (34)]. Next to the question whether the infant or childhood complex of emotions and temperament is "personality" [as the cognitive maturity that is required for most fine-grained and differentiated personality self-descriptions and our narrative identity typically emerges over early adolescence, see De Pauw (26), McAdams (35), and Soto et al. (36) $]^{2}$, it also

\footnotetext{
${ }^{2}$ Several aspects of our personality go beyond our inborn temperamental corevia sociocultural influences that are specific to the context in which you acquire your personality-including social cognition and self-related perceptions such as self-esteem and paranoia and social emotions like pride/guilt/shame, and cognitive adaptations to our social world such as the contents of thoughts, attitudes, values, beliefs, morals, needs and goals, as well as the concepts, schema's, and life narratives and identities which subsume tasks, goals, projects, tactics, defenses, values, and other developmental, motivational, and/or strategic concerns that contextualize individual lives in time, place, and role performances. Most of these personality components cannot be distinguished in young children as humans typically develop them over adolescence.
}

remains doubtful whether the other broadband factors openness, agreeableness, or conscientiousness/effortful control are more easily and reliably observable in human infants and children [e.g., Goldberg (37) and Mervielde et al. (38)], primates (39), or adults $(40,41)$ and their environments [e.g., Gosling (42)].

A third limitation is that frustration was not mentioned once, despite the strong prospective link between temperamental frustration in children and adolescents and the development of both internalizing (self-directed) and externalizing (otherdirected) problems [e.g., Caspi et al. (32) and Jeronimus et al. (43)]. Space constraints may have limited the number of lowerorder facets of neuroticism that could be reviewed (see Table 2 on page 239), but frustration is a key feature and temperamental precursor of neuroticism in youth [e.g., Jeronimus et al. (33), Putnam et al. (44), and Rothbart (45)] and adults (46), and if frustration was not part of any of the neuroticism questionnaires that were reviewed, this may indicate a notable limitation in the field of neuroticism assessment. For example, frustration (i.e., unexpected non-reward) may lead to irritability (sensitivity/excitability) but could also propel positive processes other than anger (displeasure/hostility), anxiety, or sadness [see Jeronimus et al. (33)], which are all prominent states within the neuroticism domain. I wholeheartedly agree with Brandes and Tackett that we must untangle which aspects of the multifaceted neuroticism construct predict what outcomes in more detail [cf. Hill et al. (25)], via the study of "personality nuances" [e.g., Mõttus et al. (47)] and the inclusion of individual dynamics [e.g., Jayawickreme et al. (48) and Jeronimus and Reitsema (49)], and 
we have only started to explore such questions. For example, the concurrent and prospective associations between neuroticism and somatic distress [as mentioned by Brandes and Tackett (1), p. 241; see Cuijpers et al. (17), Costa and McCrae (50), and Rosmalen et al. (51)] might primarily reflect vigilance (24) and overlap in semantics and negative affect [e.g., De Gucht et al. $(52,53)$ and van Diest et al. (54)].

Finally, the review by Brandes and Tackett missed a recent meta-analysis of the prospective associations between neuroticism and psychopathology with 59 longitudinal/prospective studies and 444.313 participants (55). This meta-analysis showed prospective associations between neuroticism and symptoms/diagnosis of anxiety, depression, and non-specific mental distress $(d=0.50-0.70)$ and considerably weaker prospective associations with substance abuse and thought disorders/symptoms $(d=0.03-0.20)$. After adjustment for baseline symptoms and psychiatric history the prospective associations between neuroticism and internalizing phenomena were reduced by half $(d=0.10-0.40)$, whereas the association with substance abuse and thought problems were not attenuated. Prospective associations were four times larger over short ( $<4$ year) than long ( $\geq 4$ years) follow-up intervals, suggesting a substantial decay of the association with increasing time intervals. Adjusted effects

\section{REFERENCES}

1. Brandes CM, Tackett JL. Contextualizing neuroticim in the Hierarchical Taxonomy of Psychopathology. J Res Pers. (2019) 81:238-45. doi: 10.1016/j.jrp.2019.06.007

2. Kotov R, Krueger RF, Watson D, Achenbach TM, Althoff RR, Bagby RM., et al. The Hierarchical Taxonomy of Psychopathology (HiTOP): a dimensional alternative to traditional nosologies. J Abnormal Psychol. (2017) 126:454. doi: $10.1037 /$ abn0000258

3. American Psychiatric Association. Diagnostic and Statistical Manual of Mental Disorders. 5th ed or DSM-5. Washington, DC: APA (2013). doi: 10.1176/appi.books.9780890425596

4. Fisher AJ, Medaglia JD, Jeronimus BF. Lack of group-to-individual generalizability is a threat to human subjects research. Proc Natl Acad Sci USA. (2018) 115:E6106-15. doi: 10.1073/pnas. 1711978115

5. Jeronimus BF. Chapter 7: Dynamic system perspectives on Anxiety and Depression. In: Kunnen ES, de Ruiter NMP, Jeronimus BF, van der Gaag MA, editors. Psychosocial Development in Adolescence: Insights from the Dynamic Systems Approach. London: Routledge Psychology (2019). p. 100-126.

6. Molenaar PC. A manifesto on psychology as idiographic science: Bringing the person back into scientific psychology, this time forever. Measurement. (2004) 2:201-18. doi: 10.1207/s15366359mea0204_1

7. Kuppens P, Oravecz Z, Tuerlinckx F. Feelings change: accounting for individual differences in the temporal dynamics of affect. J Pers Soc Psychol. (2010) 99:1042. doi: 10.1037/a0020962

8. Wichers M. The dynamic nature of depression: a new micro-level perspective of mental disorder that meets current challenges. Psychol Med. (2014) 44:1349-60. doi: 10.1017/S0033291713001979

9. Hopwood CJ. Interpersonal dynamics in personality and personality disorders. Eur J Pers. (2018) 32:499-524. doi: 10.1002/ per. 2155

10. Mobbs AE. An atlas of personality, emotion and behaviour. PLoS ONE. (2020) 15:e0227877. doi: 10.1371/journal.pone.0227877

11. Durbin CE, Hicks BM. Personality and psychopathology: a stagnant field in need of development. Eur J Pers. (2014) 28:362-86. doi: 10.1002/per.1962 were only slightly larger over short vs. long time intervals, however, which suggests that high neuroticism indexes a risk constellation that exists years prior to the development and onset of all measured mental disorders. Admittedly, such prospective associations do not rule out the spectrum and scar model-see Ormel et al. (56) or Tackett et al. (57) for elaborations, for which novel studies are required [e.g., Bos et al. (58); Goldstein et al. (59)]. Nonetheless, these prospective associations between neuroticism and psychopathology clearly support the integration of emotional, mood, and personality processes across multiple time scales, which may be required to give the HiTOP model mechanistic substance at the individual level and expand our understanding of the dynamic link between neuroticism, psychopathology, and (un)happiness.

\section{AUTHOR CONTRIBUTIONS}

The author confirms being the sole contributor of this work and has approved it for publication.

\section{FUNDING}

BJ was supported by a NWO Veni grant 016.195.405.
12. Ormel J, Laceulle OM, Jeronimus BF. Why personality and psychopathology are correlated: a developmental perspective is a first step but more is needed. Eur J Pers. (2014) 28:396-8. doi: 10.1002/per.1971

13. Kunnen ES, De Ruiter NMP, Jeronimus BF, van der Gaag MA. Psychosocial Development in Adolescence: Insights from the Dynamic Systems Approach. New York, NY: Routledge Psychology (2019). doi: 10.4324/9781315165844

14. Kendler KS, Zachar P, Craver C. What kinds of things are psychiatric disorders? Psychol Med. (2011). 41, 1143-1150. doi: 10.1017/S0033291710001844

15. Nickels MK, Nelson CE. Beware of nuts \& bolts: putting evolution into the teaching of biological classification. Am Biol Teach. (2005) 67:283-9. doi: 10. 1662/0002-7685(2005)067[0283:BONBPE]2.0.CO;2

16. Hamaker EL, Wichers M. No time like the present: discovering the hidden dynamics in intensive longitudinal data. Curr Dir Psychol Sci. (2017) 26:10-5. doi: $10.1177 / 0963721416666518$

17. Cuijpers P, Smit F, Penninx BW, de Graaf R, ten Have M, Beekman AT. Economic costs of neuroticism: a population-based study. Arch Gen Psychiatry. (2010) 67:1086-93. doi: 10.1001/archgenpsychiatry.2010.130

18. van der Krieke L, Jeronimus BF, Blaauw FJ, Wanders RB, Emerencia AC, Schenk HM., et al. HowNutsAreTheDutch (HoeGekIsNL): a crowdsourcing study of mental symptoms and strengths. Int J Methods Psychiatr Res. (2016) 25:123-44. doi: 10.1002/mpr.1495

19. Abdel-Khalek A. Measuring happiness with a single-item scale. Soc Behav Pers Int J. (2006) 34:139-49. doi: 10.2224/sbp.2006.34.2.139

20. Friedman HS. Long-term relations of personality and health: dynamisms, mechanisms, tropisms. J Pers. (2000) 68:1089-107. doi: 10.1111/1467-6494.00127

21. Turiano NA, Mroczek DK, Moynihan J, Chapman BP. Big 5 personality traits and interleukin-6: evidence for "healthy Neuroticism" in a US population sample. Brain Behav Immun. (2013) 28:83-9. doi: 10.1016/j.bbi.2012.10.020

22. Weston SJ, Jackson JJ. Identification of the healthy neurotic: personality traits predict smoking after disease onset. J Res Pers. (2015) 54:61-9. doi: 10.1016/j.jrp.2014.04.008

23. Bos EH, Snippe E, de Jonge P, Jeronimus BF. Preserving subjective wellbeing in the face of psychopathology: buffering effects of personal strengths and resources. PLoS ONE. (2016) 11:e0150867. doi: 10.1371/journal.pone.0150867 
24. Tamir M, Robinson MD, Solberg EC. You may worry, but can you recognize threats when you see them?; Neuroticism, threat identifications, and negative affect. J Pers. (2006) 74:1481-506. doi: 10.1111/j.1467-6494.2006.00417.x

25. Hill WD, Weiss A, Liewald DC, Davies G, Porteous DJ, Hayward C., et al. Genetic contributions to two special factors of neuroticism are associated with affluence, higher intelligence, better health, and longer life. Mol Psychiatry. (2019) 1:1-19. doi: 10.1038/s41380-019-0387-3

26. Soto CJ, John OP, Gosling SD, Potter J. The developmental psychometrics of big five self-reports: acquiescence, factor structure, coherence, and differentiation from ages 10 to 20. J Pers Soc Psychol. (2008) 94:718. doi: $10.1037 / 0022-3514.94 .4 .718$

27. Piontelli A. Twins: From Fetus to Child. London: Routledge (2004). doi: 10.4324/9780203359525

28. Buss AH. Pathways to Individuality: Evolution and Development of Personality Traits. Washington, DC: American Psychological Association (2011).

29. Houben M, Van Den Noortgate W, Kuppens P. The relation between shortterm emotion dynamics and psychological well-being: a meta-analysis. Psychol Bull. (2015) 141:901. doi: 10.1037/a0038822

30. Jeronimus BF. Environmental influences on neuroticism: A story about emotional (in) stability (Ph.D. thesis). Rijksuniversiteit Groningen, Groningen, Netherlands (2015).

31. Reitsema AM, Jeronimus BF, van Dijk M, de Jonge P. Emotion dynamics in children and adolescents: A systematic and multi-level meta-analytic and descriptive review. Preprint (2019).

32. Caspi A, Houts RM, Belsky DW, Harrington H, Hogan S, Ramrakha $\mathrm{S}$, et al. Childhood forecasting of a small segment of the population with large economic burden. Nat Hum Behav. (2016) 1:0005. doi: 10.1038/s41562-016-0005

33. Jeronimus BF, Laceulle OM. Frustration. In: Zeigler-Hill V, Shackelford TK, editors. Encyclopedia of Personality and Individual Differences. New York, NY: Springer. (2017). p. 1-8. doi: 10.1007/978-3-319-28099-8_815-1

34. Hirschmüller S, Egloff B, Schmukle SC, Nestler S, Back MD. Accurate judgments of neuroticism at zero acquaintance: a question of relevance. J Pers. (2015) 83:221-8. doi: 10.1111/jopy.12097

35. De Pauw SS. Chapter 12: Childhood personality and temperament. In: Widiger $\mathrm{T}$, editors. The Oxford Handbook of the Five Factor Model. New York, NY: Oxford Press (2017). p. 243-80. doi: 10.1093/oxfordhb/9780199352487.013.21

36. McAdams DP. The Art and Science of Personality Development. New York, NY: Guilford Publications (2015).

37. Goldberg LR. Analyses of Digman's child-personality data: derivation of BigFive factor scores from each of six samples. J. Pers. (2001) 69:709-44. doi: 10.1111/1467-6494.695161

38. Mervielde I, Buyst V, De Fruyt F. The validity of the Big-Five as a model for teachers' ratings of individual differences among children aged 4-12 years. Pers Individ Diff. (1995) 18:525-34. doi: 10.1016/0191-8869(94)00175-R

39. King JE, Weiss A, Sisco MM. Aping humans: age and sex effects in chimpanzee (Pan troglodytes) and human (Homo sapiens) personality. J Comp Psychol. (2008) 122:418. doi: 10.1037/a0013125

40. Connolly JJ, Kavanagh EJ, Viswesvaran C. The convergent validity between self and observer ratings of personality: a meta-analytic review. Int J Sel Assess. (2007) 15:110-7. doi: 10.1111/j.1468-2389.2007.00371.x

41. Kim H, Di Domenico SI, Connelly BS. Self-other agreement in personality reports: a meta-analytic comparison of self-and informant-report means. Psychol Sci. (2019) 30:129-38. doi: 10.1177/0956797618810000

42. Gosling S. (2018) Snoop: What Your Stuff Says About You. London: Profile Books.

43. Jeronimus BF, Riese H, Oldehinkel AJ, Ormel J. Why does frustration predict psychopathology? Multiple prospective pathways over adolescence: A TRAILS study. Eur J Pers. (2017) 31:85-103. doi: 10.1002/per.2086

44. Putnam SP, Ellis SK, Rothbart MK. The structure of temperament from infancy through adolescence. In: Eliasz A, Engleneiter A, editors. Advances in Research on Temperament. Berlin: Pabst Scientist Publisher (2001). p. 165-82.

45. Rothbart MK. Becoming Who We Are: Temperament And Personality In Development. New York, NY: Guilford Press (2011).
46. Egan V, Lewis M. Neuroticism and agreeableness differentiate emotional and narcissistic expressions of aggression. Pers Individ Diff. (2011) 50:845-50. doi: 10.1016/j.paid.2011.01.007

47. Mõttus R, Sinick J, Terracciano A, Hrebíčková M, Kandler C, Ando J., et al. Personality characteristics below facets: a replication and metaanalysis of cross-rater agreement, rank-order stability, heritability, and utility of personality nuances. J Pers Soc Psychol. (2018) 117:e35-50. doi: $10.1037 /$ pspp0000202

48. Jayawickreme E, Zachry CE, Fleeson W. Whole trait theory: an integrative approach to examining personality structure and process. Pers Individ Diff. (2019) 136:2-11. doi: 10.1016/j.paid.2018.06.045

49. Jeronimus BF, Reitsema AM. Yes, let's enrich the Big Five personality taxonomy! But how far do we go? Eur J Pers. (2018) 32:552-3. doi: 10.1002/per.2174

50. Costa PT Jr, McCrae RR. Neuroticism, somatic complaints, and disease: is the bark worse than the bite? J Pers. (1987) 55:299-316. doi: 10.1111/j.1467-6494.1987.tb00438.x

51. Rosmalen JG, Neeleman J, Gans RO, de Jonge P. The association between neuroticism and self-reported common somatic symptoms in a population cohort. J Psychosom Res. (2007) 62:305-11. doi: 10.1016/j.jpsychores.2006.10.014

52. De Gucht V, Fischler B, Heiser W. Neuroticism, alexithymia, negative affect, and positive affect as determinants of medically unexplained symptoms. Pers Individ Diff. (2004) 36:1655-67. doi: 10.1016/j.paid.2003.06.012

53. De Gucht V, Fischler B, Heiser W. Personality and affect as determinants of medically unexplained symptoms in primary care: a follow-up study. $J$ Psychosom Res. (2004) 56:279-85. doi: 10.1016/S0022-3999(03)00127-2

54. Van Diest I, De Peuter S, Eertmans A, Bogaerts K, Victoir A, Van den Bergh O. Negative affectivity and enhanced symptom reports: differentiating between symptoms in men and women. Soc Sci Med. (2005) 61:1835-45. doi: 10.1016/j.socscimed.2005.03.031

55. Jeronimus BF, Kotov R, Riese H, Ormel J. Neuroticism's prospective association with mental disorders halves after adjustment for baseline symptoms and psychiatric history, but the adjusted association hardly decays with time: a meta-analysis on 59 longitudinal/prospective studies with 443313 participants. Psychol Med. (2016) 46:2883-906. doi: $10.1017 /$ S0033291716001653

56. Ormel J, Jeronimus BF, Kotov R, Riese H, Bos EH, Hankin B. et al. Neuroticism and common mental disorders: meaning and utility of a complex relationship. Clin Psychol Rev. (2013) 33:686-97. doi: 10.1016/j.cpr.2013.04.003

57. Tackett JL. Evaluating models of the personality-psychopathology relationship in children and adolescents. Clin Psychol Rev. (2006) 26:584-99. doi: 10.1016/j.cpr.2006.04.003

58. Bos EH, Ten Have $M$, van Dorsselaer S, Jeronimus BF, de Graaf $R$, de Jonge P. Functioning before and after a major depressive episode: pre-existing vulnerability or scar? A prospective three-wave populationbased study. Psychol Med. (2018). 48, 2264-2272. doi: 10.1017/S0033291717 003798

59. Goldstein BL, Perlman G, Eaton NR, Kotov R, Klein DN. Testing explanatory models of the interplay between depression, neuroticism, and stressful life events: a dynamic trait-stress generation approach. Psychol Med. (2019) 1-10. doi: 10.1017/S003329171 9002927. [Epub ahead of print].

Conflict of Interest: The author declares that the research was conducted in the absence of any commercial or financial relationships that could be construed as a potential conflict of interest.

Copyright (C) 2020 Jeronimus. This is an open-access article distributed under the terms of the Creative Commons Attribution License (CC BY). The use, distribution or reproduction in other forums is permitted, provided the original author(s) and the copyright owner(s) are credited and that the original publication in this journal is cited, in accordance with accepted academic practice. No use, distribution or reproduction is permitted which does not comply with these terms. 